\title{
Early Pregnancy Maternal Body Composition, Infant Feeding and Infant Body Composition
}

\author{
L. Mullaney ${ }^{1}$, A. Doolan ${ }^{2}$, A. O’Higgins ${ }^{3}$, M. Sheridan-Pereira ${ }^{2}$, D. McCartney ${ }^{1}$ \\ and M. J. Turner ${ }^{3}$ \\ ${ }^{1}$ School of Biological Sciences, Dublin Institute of Technology, Dublin 8, Republic of Ireland, ${ }^{2}$ Department of \\ Pediatrics, Trinity College, Dublin 2, Republic of Ireland and ${ }^{3}$ UCD Centre for Human Reproduction, CWIUH, \\ Dublin 8, Republic of Ireland
}

Maternal factors are thought to strongly influence a child's risk of obesity and subsequent metabolic dysfunction ${ }^{(1,2)}$. Children born to obese women have been shown to be at increased risk of obesity and diabetes in adolescence, adulthood and in later life ${ }^{(3,4)}$. Infant feeding patterns may also influence lifelong health. Exclusive breastfeeding is recommended for the first 6 months of life, with the introduction of complimentary foods and continuous breastfeeding thereafter ${ }^{(5,6)}$. The earlier introduction of solids has been associated with overweight in adulthood ${ }^{(7)}$. However, few studies have examined the relationship between maternal pregnancy body composition and infant body composition in the first year of life.

This prospective observational study examined the relationships between maternal body composition in the first trimester, infant feeding practices and infant body composition at four months of age.

Women were recruited at their convenience in July 2012 after sonographic confirmation of a singleton pregnancy in the first trimester. Maternal body composition was measured using 8-electrode bioelectrical impedance analysis. Infant body composition was measured using air displacement plethysmography at 4 months of age. Infant feeding practices were assessed at 4 months of age.

Of the 100 mother-infant pairs, the mean maternal age was $30 \cdot 3$ years $( \pm 5 \cdot 4)$. The mean maternal BMI was $26 \cdot 5 \mathrm{~kg} / \mathrm{m}^{2}( \pm 5 \cdot 7)$ and $22 \%$ were obese. The mean maternal body fat $\%$ was $32 \cdot 4 \%( \pm 7 \cdot 7)$. Mean birth weight was $3 \cdot 4 \mathrm{~kg}( \pm 0 \cdot 6)$ and infant weight at 4 months was $6 \cdot 4 \mathrm{~kg}( \pm 0 \cdot 6)$. The mean infant body fat percentage at birth was $10 \cdot 8 \%(1-23 \%)$ and at four months was $25 \%(13-$ $33 \%$ ). Maternal percentage body fat in the first trimester was not predictive of infant percentage body fat at four months of age. By four months of age $62 \%$ of mothers had introduced solids. Of 91 of the women, 38 women $(41 \cdot 8 \%)$ reported not breastfeeding during this latest pregnancy. Breastfeeding or the introduction of solids had no influence on infant composition at this point.

Influences on early infant growth are complex. In this pilot, we did not find that maternal body composition in the first trimester of pregnancy or infant feeding practices influenced infant adiposity at four months of age.

1. Barker J, Osmond C, Simmonds SJ, Wield JA (1993) Br MedJ 306, 422-426

2. Monasta L, Batty GD, Cattaneo A, Lutje V, Ronfani L, van Lenthe FJ, Brug J (2010) Obesity Reviews 11, 695-708.

3. Baker JL, Michaelsen KF, Rasmussen KM, Sorensen TI (2004) Am J ClinNutr 80, 1579-1588.

4. Satpathy HK, Fleming A, Frey D, Barsoom M, Satpathy C, Khandalavala J (2008) Postgrad Med 120, 01-09.

5. World Health Organisation (2001) WHO Publications, Geneva.

6. American Academy of Paediatrics (2012) Paediatrics 129, 827-841.

7. Schack-Nielsen L, Sorensen T, Mortensen EL, Michaelsen KF (2010) Am J ClinNutr 91, 619-627. 